\title{
Breaking the silence
}

\author{
VIDYA VISWANATH
}

Pathologist, A S Raja Voluntary Blood Bank and Assistant Professor, Department of Pathology, GITAM Dental College and Hospital, Visakhapatnam 530 045 INDIA

e-mail: drvidya21@gmail.com

\section{AIDS Sutra: untold stories from India. Random House India: 2008. 334 pages. ISBN 13579108642}

"Literature... has been, in a way a great ally of science in making us discern the world better-a hugely important contribution that still does not get adequate attention," observes Amartya Sen in his thought-provoking foreword to AIDS Sutra - untold stories from India.

The book is a testimony to this statement for various reasons. Sixteen eminent authors have used their medium to tell us about the human stories associated with HIV/ AIDS. They have spent time, interacted and empathised with the protagonists and this comes across in their touching portrayals and published photographs.

We also need to remind ourselves that AIDS is a disease like no other in medicine. Along with social, cultural and behavioural issues it is associated with stigma, discrimination and very little sympathy. Moreover, the nature and reach of this disease with its varied modes of spread emphasise that it is important to know your patient better than the disease. As physicians, we just see HIV/AIDS as a global epidemic and a challenge to medicine. Reading these stories gives us an insight into the social issues related to the disease which are equally important in preventing and controlling the epidemic.

To the general reader, the book helps in understanding the disease through real life experiences and this can be a step in sensitising society towards HIV/AIDS.

Society has made women double victims of HIV/AIDS. They are vulnerable not just to the disease but also to the trauma of stigmatisation, domestic violence and unequal treatment. A number of essays in the book centre around female sex workers and women living with HIV/AIDS and common to all of them is the threat of contracting the disease if they haven't and the dread of abandonment if they have.

Another group of people who are treated with revulsion are the third gender. Salman Rushdie in his essay wonders how we can humiliate the Ardhanaris and also worship Ardhanarishwara. Other contributions bring out the torment faced by men who have sex with men and this again focuses on the urgent need to revamp old laws and legalise certain sexual practices to encourage openness. Talking about laws brings into picture its guardians-the police-who are sadly both victims and offenders. Through the blood they come in contact with, and the free sex they demand, they also acquire the virus.
Sonia Faleiro gives an account of this vicious nexus between policemen, sex workers and outreach workers.

Amit Chaudhari's 'Healing' takes us to the doctors in Mumbai who are working towards controlling the disease and are seeing encouraging results with antiretroviral treatment. Given the present scenario, the future demands many more such committed professionals along with huge investments in infrastructure. Unless great progress is made in prevention, the number of people living with HIV will outstrip the resources available for treatment. The enormity of this situation is touched upon in Jaspreet Singh's essay 'Bhoot ki Kahaniyan'. When he interacts with AIDS orphans and reminisces that he met only 34 and wonders where the other 1.9 million are, it is a haunting moment in the book.

Stoic strength is seen in many of the stories but one that is unique in this respect is Nikita Lalwani's contribution. This is the story of a successful doctor whose HIV positive status is revealed to him by all his family members following a shocking breach of confidentiality by the hospital where he was a blood donor for his relative. Stigmatised, he migrates, finds acceptance as a doctor in Chennai at a leading centre for AIDS research and then takes his battle for breach of confidentiality, followed by marital rights for HIV positive people, to the Supreme Court. Ironically, though the case is "Mr X versus Hospital Y" his name gets splashed in the papers. Today he is content with his work at the centre and runs a marriage counselling centre for HIV positive people. Besides marvelling at his fortitude this essay stresses the importance of confidentiality and human rights. There is also a message in it for us - to discourage directed blood donations and reduce relative blood donation. Apart from the immunological risks involved in directed donation, a reactive screening report leads to compromise in donor confidentiality and can damage relationships when the family is already under strain. Encouraging regular voluntary blood donation is the best way to ensure both donor privacy and patient safety. As regards the issue of blood donor disclosure, NACO has taken a much needed step in the right direction. It is now the right of the donor to know his screening status and also the responsibility of the blood bank to disclose the information to the donor and refer all those who test positive for counselling.

To conclude, trying to close the gap between people living with HIV/AIDS and the community could be our tribute to those who have contributed to this anthology. 